\title{
Short communication: Sensory profile and acceptability of a cow milk cheese manufactured by adding jenny milk
}

\author{
C. Cosentino, ${ }^{1}$ D. Faraone, R. Paolino, P. Freschi, and M. Musto \\ SAFE School of Agricultural, Forestry, Food, and Environmental Sciences, University of Basilicata, Viale dell'Ateneo Lucano 10, \\ Potenza 85100, Italy
}

\begin{abstract}
The addition of jenny milk during cheesemaking has been recommended as a viable alternative to egg lysozyme for controlling late blowing defects. However, little is known on the sensory properties of the cheeses made with jenny milk. In this study, the effect of the addition of jenny milk during cheesemaking on sensory properties and consumer acceptability of cheese was evaluated. A sensory profile was carried out by 10 trained panelists on 4 cow milk cheese types. Two types of cheeses were made by adding jenny milk to cow milk during cheesemaking; the cheeses were then left to ripen for 45 and $120 \mathrm{~d}$. The remaining 2 cheese types were made with only cow milk and were also left to ripen for 45 and $120 \mathrm{~d}$. The attributes generated by a quantitative descriptive analysis sensory panel were effective for discriminating the 4 products. Among them, added jenny milk samples aged for $45 \mathrm{~d}$ had the highest intensity of some appearance descriptors (structure and color uniformity), as well as the highest intensity of sweetness. The analysis of acceptability data obtained from 89 consumers showed that added jenny milk aged for $45 \mathrm{~d}$ was the most preferred type of cheese, whereas no significant differences were found among the other products, which had higher intensity of bitter, salty, acid milk, and so on.
\end{abstract}

Key words: sensory analysis, consumer acceptability, jenny milk, cheese

\section{Short Communication}

In recent decades there has been a renewed interest and research in jenny milk (Guo et al., 2007; Cosentino et al., 2012, 2013, 2015; Fantuz et al., 2012; Martemucci and D'Alessandro, 2012). This interest is first motivated by the chemical composition and nutrient contents of jenny milk, which have made it very similar to human milk (Guo et al., 2007). Besides, jenny milk

Received July 13, 2015.

Accepted September 6, 2015.

${ }^{1}$ Corresponding author: carlo.cosentino@unibas.it is considered as a good replacer for cow milk in feeding children with severe IgE-mediated cow milk protein allergies (Guo et al., 2007; Nazzaro et al., 2010; Galassi et al., 2012). Due to its low lipid content, it is also capable of providing benefits for a low-fat diet plan (Guo et al., 2007; Nazzaro et al., 2010), as well as for the treatment of human immune-related diseases and in the prevention of atherosclerosis (Tafaro et al., 2007).

Another aspect of growing interest is related to the possible use of some components of jenny milk. Among them, the lysozyme contained in jenny milk is of special interest. This bacteriolytic protein is a nonspecific immunoprotective factor, whose powerful antibacterial activity is due to its capacity to catalyze the hydrolysis of the $\beta(1-4)$ glycosidic links between $\mathrm{N}$-acetylmuramic acid and $\mathrm{N}$-acetylglucosamine in the bacterial cell wall polysaccharides, working in synergy with lactoferrin and immunoglobulins (Marseglia et al., 2013). The lysozyme content in jenny milk ranges from 1.0 to 3.7 $\mathrm{mg} / \mathrm{mL}$ (Zhang et al., 2008; Galassi et al., 2012) and is much higher than in cow $(0.18 \mu \mathrm{g} / \mathrm{mL})$, buffalo $(0.15$ $\mu \mathrm{g} / \mathrm{mL})$, ewe $(0.20 \mu \mathrm{g} / \mathrm{mL})$, or goat milk $(0.25 \mu \mathrm{g} /$ $\mathrm{mL}$; Kumari and Mathur, 1981; Fratini et al., 2006; Scharfen et al., 2007).

Previous studies have shown that donkey lysozyme can be successfully employed for controlling the growth of the bacteria responsible of late blowing in cheese (Galassi et al., 2012; Cosentino et al., 2013, 2015). For instance, Galassi et al. (2012) compared 2 groups of hard cheeses, one obtained by adding jenny milk (10 $\mathrm{L} / 500 \mathrm{~kg}$ ) and the other by adding lysozyme from hen egg white $(1.6 \mathrm{~g} / 100 \mathrm{~kg})$. Overall, their results showed no significant differences between the groups in terms of technological and sensorial aspects. The effectiveness of jenny milk lysozyme as a substitute of egg lysozyme has been recently confirmed by Cosentino et al. (2013, 2015). In these studies, jenny milk was added to ewe and cow milk during cheesemaking. In both cases, the authors found jenny milk to be an important inhibitor of late blowing in cheese. Moreover, a consumer evaluation found no significant differences between semihard cow cheeses obtained with and without jenny milk (Cosentino et al., 2015). 
Table 1. Experimental design for cheese made with (CJ) and without (CC) jenny milk

\begin{tabular}{lcccc}
\hline Code & Cow milk, $\mathrm{L}$ & Jenny milk, $\mathrm{L}$ & Ripening time, $\mathrm{d}$ & Cheeses, $\mathrm{n}$ \\
\hline CJ-45 & 40 & 3.2 & 45 & 8 \\
CC-45 & 40 & 0 & 45 & 8 \\
CJ-120 & 40 & 3.2 & 120 & 8 \\
CC-120 & 40 & 0 & 120 & 8 \\
\hline
\end{tabular}

The results of previous studies are important not only from a microbiological point of view, but also from a technological one, as they led to the creation of new dairy products made with jenny milk. However, to date, a comprehensive study on the characterization of sensory properties of these products is still not available. In the food industry, sensory analysis is recognized as a standard tool for both the development of new products and in checking and improving their quality. A sensory analysis by an expert panel may be very useful for identifying sensory attributes characterizing the cheese made with jenny milk. By using descriptive profiling techniques, such as quantitative flavor profiling (Stampanoni, 1993), the Spectrum method (Meilgaard et al., 2006), and quantitative descriptive analysis (QDA; Stone et al., 2004), several specific sensory profile have been developed for different types of cheeses, such as Scamorza (Braghieri et al., 2015), Caciottina (Papetti and Carelli, 2013), Cheddar (Young et al., 2004), Swiss cheese (Liggett et al., 2008), and so on.

The relationship between sensory profile and consumer acceptability is another crucial factor affecting the success of foods and drinks. Concerning cheese, several studies have been carried out to understand what sensory properties drive consumer liking (Pagliarini et al., 1997; Ritvanen et al., 2005; Ryffel et al., 2008). In the present study, QDA was applied to establish the sensory attributes that characterize the profile of a cow milk cheese manufactured by adding jenny milk and with 2 different ripening times (45 and $120 \mathrm{~d}$ ). The relationship between sensory attributes and consumer acceptability was investigated to identify those attributes that most affect the liking of this kind of cheese.

Fresh raw cow milk and jenny milk were collected the same day from 2 different farms by a mechanical milking apparatus. After collection, milk samples were immediately refrigerated at $4^{\circ} \mathrm{C}$ and transported to the laboratory to determine protein, fat, and lactose content according to the International Dairy Federation standard (ISO, 2013), as well as DM and ash content according to AOAC (1990). Cow milk contained, on average, $3.29 \%$ protein, $3.69 \%$ fat, $4.05 \%$ lactose, $11.67 \%$ $\mathrm{DM}$, and $0.49 \%$ ash content. Jenny milk had the following composition: $1.69 \%$ protein, $1.31 \%$ fat, $6.43 \%$ lactose, $9.62 \% \mathrm{DM}$, and $0.42 \%$ ash content.
Cow and jenny milk were used to produce cheese according to procedures described by Cosentino et al. (2015). Cow milk was first pasteurized $\left(65^{\circ} \mathrm{C}\right.$ for 30 min) and then cooled to $37^{\circ} \mathrm{C}$. Subsequently, a fixed amount $(40 \mathrm{~L})$ of pasteurized cow milk poured into 4 vats. A group of vats was created by adding $3.2 \mathrm{~L}$ of raw jenny milk to 2 vats $(\mathbf{C J})$. The remaining 2 vats contained only cow milk and were used as control group (CC). Kid rennet $(0.2 \mathrm{~g} / \mathrm{L}$; activity 1:10,000; Caglio Camoscio CSC 95/75, DMS, Segrate, Italy) was added to the vats of each group. After $50 \mathrm{~min}$, the curds of each vat were cut (diameter of particles $=0.5$ $\mathrm{cm}$ ) and pressed into cylindrical molds (diameter $=14$ $\mathrm{cm}$, height $=8 \mathrm{~cm}$ ). After $24 \mathrm{~h}$ of draining, cheeses were salted in containers with sterile brine $(200 \mathrm{~g} / \mathrm{L}$ of $\mathrm{NaCl}, \mathrm{pH} 5.40$ ) for $2 \mathrm{~h}$ and then stored at $20^{\circ} \mathrm{C}$ for 4 d. Finally, both cheese groups were divided into 2 subgroups, each composed of 4 cheeses, which were left in a ripening room $\left(13-15^{\circ} \mathrm{C}\right.$, air humidity $\left.=80-85 \%\right)$ for 2 different time periods: 45 and $120 \mathrm{~d}$ (Table 1). The whole experiment was repeated twice.

The QDA of the cheeses was carried out by a panel of 10 members ( 5 male and 5 female, age $22-53$ yr) who evaluated the cheeses under the supervision of a leader to generate and agree upon sensory descriptors of odor, flavor, taste, and texture. After training, the panelists developed a final descriptor list composed of 13 descriptive attributes, whose definitions, along with the reference material used to anchor the panel scores, are shown in Table 2. An unstructured line scale was used for rating attribute intensity. The left side of the scale corresponded to the lowest intensity of each attribute (value 0), whereas the right side to the highest intensity (value 100). Triplicate sessions were performed in separate booths equipped with a computerized system and sensory software (FIZZ ver.1.3.1, Biosystèmes, Couternon, France), where the sensory data were recorded directly. Samples were assigned 3-digit codes and their serving orders were randomized by the software. Evaluations took place under red fluorescent lights to mask color differences in the samples, except during the evaluation of cheese appearance, when only fluorescent lighting was used. Pieces of cracker and water were provided for cleansing the palate between samples.

The acceptability of the 4 cheese types [i.e., CJ and CC aged 45 and $120 \mathrm{~d}$ (CJ-45, CJ-120, CC-45, and 
Table 2. Sensory descriptors, definition, and reference materials used during panel training and quantitative descriptive analysis sessions

Reference materials for anchoring the extreme 2 points of the scale ${ }^{1}$

\begin{tabular}{|c|c|c|c|c|}
\hline \multirow{2}{*}{ Attribute } & \multirow[b]{2}{*}{ Descriptor } & \multirow[b]{2}{*}{ Definition } & \\
\hline & & & Low & High \\
\hline \multirow[t]{2}{*}{$\overline{\text { Appearance }}$} & Color uniformity & $\begin{array}{l}\text { Overall uniformity in color, which } \\
\text { can be reduced by shades or tones }\end{array}$ & $\begin{array}{l}\text { 8-mo ripened Caciocavallo } \\
\text { cheese }\end{array}$ & Fontina $\mathrm{PDO}^{2}$ cheese \\
\hline & Structure uniformity & $\begin{array}{l}\text { Overall uniformity in structure, } \\
\text { which can be reduced by fissures, } \\
\text { holes, or cracks }\end{array}$ & Asiago PDO cheese & Fontina PDO cheese \\
\hline \multirow[t]{2}{*}{ Odor } & Milk & Odor arising from fresh milk & Fontina PDO cheese & Mozzarella cheese \\
\hline & Cooked milk & Odor associated with cooked milk & UHT milk & $\begin{array}{l}\text { Milk brought to boiling } \\
\text { point, and then cooled }\end{array}$ \\
\hline \multirow[t]{2}{*}{ Flavor } & Cooked milk & Flavor associated with cooked milk & UHT milk & $\begin{array}{l}\text { Milk brought to boiling } \\
\text { point, and then cooled }\end{array}$ \\
\hline & Acid milk & Flavor of fermented milk products & UHT milk & Low-fat yogurt \\
\hline \multirow[t]{2}{*}{ Taste } & Sweet & $\begin{array}{l}\text { Fundamental taste associate01d } \\
\text { with sucrose or fructose }\end{array}$ & $2 \%$ sucrose solution & $10 \%$ sucrose solution \\
\hline & Sour & $\begin{array}{l}\text { Fundamental taste associated with } \\
\text { citric acid }\end{array}$ & $1 \%$ citric acid solution & $3 \%$ citric acid solution \\
\hline Texture & Hardness & $\begin{array}{l}\text { The force needed by the jaws to bite } \\
\text { the sample into two pieces }\end{array}$ & Mozzarella cheese & $\begin{array}{l}\text { 36-mo ripened } \\
\text { Parmigiano Reggiano } \\
\text { PDO }\end{array}$ \\
\hline
\end{tabular}

${ }^{1}$ An unstructured scale, whose left side corresponded to the lowest attribute intensity (value 0) whereas the right side to the highest intensity (value 100), was used.

${ }^{2} \mathrm{PDO}=$ protected designation of origin.

CC-120, respectively)] was evaluated by 89 habitual consumers (42 male and 47 female, age 22-61 yr) of cheeses. Consumer recruitment was carried out by placing advertisements across the University of Basilicata campus. Cheese slices, identified by random 3-digit codes and served in random order under white fluorescent lighting, were evaluated by using a 9-point hedonic scale $(1=$ dislike extremely and $9=$ like extremely $)$ in individual booths using the software FIZZ (ver.1.3.1, Biosystèmes).

A preliminary 3 -factor $[1=$ cheese (4 levels); $2=$ panellists (10 levels); 3 = replications (3 levels)], 2-way ANOVA with interactions was used to evaluate the panel efficiency (Montouto-Grana et al., 2002; Pagliarini, 2002). Based on the ANOVA results, the factor cheese was significant for all descriptors, whereas the other factors, as well as the interactions, were not significant. These results showed a good reliability of the panel's judgments for each sensory descriptor. Both sensory and acceptability data were then subjected to 1-way ANOVA with cheese (4 levels) as factor. Least significant difference (LSD) mean separation test was used to detect significant differences among the cheeses.
Table 3 reports the results of the sensory profile of cheese samples. The factor cheese was significant $(P$ $<0.001)$ on all appearance descriptors. The intensity of color uniformity was not affected by the addition of jenny milk, as no differences were found between CJ and CC samples regardless the ripening time. However, in both groups, the intensity of this appearance descriptor decreased during ripening, probably for the occurrence of shades and tones. Variation in color during ripening has been described in previous studies on different types of cheese (Pompei et al., 1991; Rohm and Jaros, 1996; Buffa et al., 2001; Saldo et al., 2002). In particular, in previous studies a significant decrease in lightness, as well as a change in color to a more yellow-orange color, has been reported during ripening. For the descriptor structure uniformity, the highest mean value (69.97) was observed in CJ-45 cheese samples. This result is related to the lower occurrence of fissures, holes, and cracks in CJ cheese samples, and is consistent with a previous study on the effect of jenny milk addition on the inhibition of late blowing in semihard cheese (Cosentino et al., 2015). In their study, Cosentino et al. (2015) found that adding jenny 
Table 3. Means ${ }^{1}$ of sensory descriptors that characterized the cheese samples made with (CJ) and without (CC) jenny milk after 45 and $120 \mathrm{~d}$ of ripening

\begin{tabular}{|c|c|c|c|c|c|}
\hline \multirow[b]{2}{*}{ Attribute } & \multirow[b]{2}{*}{ Descriptor } & \multicolumn{4}{|c|}{ Cheese } \\
\hline & & CJ-45 & CC-45 & CJ-120 & CC-120 \\
\hline \multirow[t]{2}{*}{ Appearance } & Color uniformity & $78^{\mathrm{a}}$ & $77^{\mathrm{a}}$ & $65^{\mathrm{b}}$ & $64^{\mathrm{b}}$ \\
\hline & Structure uniformity & $70^{\mathrm{a}}$ & $62^{\mathrm{b}}$ & $66^{\mathrm{c}}$ & $49^{\mathrm{d}}$ \\
\hline \multirow[t]{4}{*}{ Odor } & Milk & $10^{\mathrm{a}}$ & $10^{\mathrm{a}}$ & $3^{\mathrm{b}}$ & $3^{\mathrm{b}}$ \\
\hline & Cooked milk & $32^{\mathrm{a}}$ & $36^{\mathrm{b}}$ & $10^{\mathrm{c}}$ & $10^{\mathrm{c}}$ \\
\hline & Acid milk & $40^{\mathrm{a}}$ & $40^{\mathrm{a}}$ & $44^{\mathrm{b}}$ & $51^{\mathrm{c}}$ \\
\hline & Ripened cheese & $8^{\mathrm{a}}$ & $10^{\mathrm{a}}$ & $29^{\mathrm{b}}$ & $30^{\mathrm{b}}$ \\
\hline \multirow[t]{2}{*}{ Flavor } & Cooked milk & $27^{\mathrm{a}}$ & $30^{\mathrm{b}}$ & $4^{c}$ & $5^{\mathrm{c}}$ \\
\hline & Acid milk & $34^{\mathrm{a}}$ & $37^{\mathrm{b}}$ & $38^{\mathrm{b}}$ & $43^{\mathrm{c}}$ \\
\hline \multirow[t]{4}{*}{ Taste } & Sweet & $15^{\mathrm{a}}$ & $1^{\mathrm{b}}$ & $6^{\mathrm{c}}$ & $0^{\mathrm{b}}$ \\
\hline & Salty & $58^{\mathrm{a}}$ & $59^{\mathrm{a}}$ & $64^{\mathrm{b}}$ & $69^{\mathrm{c}}$ \\
\hline & Bitter & $3^{\mathrm{a}}$ & $3^{\mathrm{a}}$ & $9^{\mathrm{b}}$ & $18^{\mathrm{b}}$ \\
\hline & Sour & $34^{\mathrm{a}}$ & $34^{\mathrm{a}}$ & $38^{\mathrm{b}}$ & $45^{\mathrm{c}}$ \\
\hline Texture & Hardness & $60^{\mathrm{a}}$ & $55^{\mathrm{b}}$ & $68^{\mathrm{c}}$ & $62^{\mathrm{d}}$ \\
\hline
\end{tabular}

${ }^{\mathrm{a}-\mathrm{d}}$ Means followed by the same letter in each row are not significantly different at the $5 \%$ level according to the Fisher's least significant difference (LSD) mean separation test.

${ }^{1}$ An unstructured scale, whose left side corresponded to the lowest attribute intensity (value 0) whereas the right side to the highest intensity (value 100), was used for each descriptor.

milk during cheese making led to the reduction of the appearance of irregular holes, cracks, and splits within the cow cheese matrix.

A significant $(P<0.001)$ effect of the type of cheese on all odor descriptors was noted. The odor of milk and cooked milk was significantly higher in both CC and CJ after 45 than $120 \mathrm{~d}$. The latter descriptor was also significantly lower in CJ-45 than in CC-45 (32.00 vs. 35.50 , respectively). Conversely, the values of ripened cheese and acid milk were significantly the highest in 120 -d ripened cheese samples. Flavor descriptors were also significantly $(P<0.001)$ affected by cheese type. In both groups, values of acid milk were lower after $45 \mathrm{~d}$ than after $120 \mathrm{~d}$; CJ samples showed the lowest values for this descriptor, regardless of the ripening time. Concerning cooked milk, after $45 \mathrm{~d}$ the value was higher in CC than in CJ (29.50 vs. 26.97, respectively), whereas no difference was found between groups after 120 d. According to Gasperi et al. (2012), milk, cooked milk, acid milk, and ripened cheese are among the most common attributes for describing the odor and flavor of cheese. Our results showed that the intensity of some of these attributes changed during ripening, regardless of the addition of jenny milk. For instance, the odor of milk scored higher in less-ripened cheeses; on the contrary, the perception of ripened cheese was higher after $120 \mathrm{~d}$ of ripening. With regard to cooked milk, this note has been found in several cheeses with different milk sources, country of origin, processing methods, and ripening times (Drake et al., 2001, 2005a,b; Rétiveau et al., 2005; Koppel et al., 2011). In a study on a Cheddar cheese flavor, Drake et al. (2005b) described cooked milk as a note prevalent in the less- ripened cheeses. In the present study, the intensity of both odor and flavor of cooked milk was higher in the 45-d-old cheeses, and, comparing the groups at this ripening time, it was higher in CC than in CJ samples. An opposite trend was found for the descriptor acid milk, as its intensity was higher in longer-ripened than in shorter-ripened cheeses; likewise, it was higher in $\mathrm{CC}$ than in CJ samples. The perception of acid milk is related to the fermentation of lactose to lactic acid by lactic acid bacteria in the form of starter cultures, or by the microflora naturally present in the raw milk and its environment (McSweeney, 2004; Kongo, 2013). In Cheddar cheese, the amount of lactic acid increased during ripening (Barlow et al., 1989), which, in turn, led to a higher perception of the acid note (Chambers et al., 2005).

Concerning taste descriptors, significant differences were observed among the cheeses $(P<0.001)$. The highest value of sweet was noted in CJ rather than CC samples. This result is related to the presence of lactose in jenny milk. According to Guo et al. (2007), the lactose content in jenny milk is relatively high, with values ranging from 5.8 to $7.4 \mathrm{~g} / 100 \mathrm{~g}$. Residual levels of lactose have been found in the curd of Cheddar, although a great part is lost as lactose in the whey, or as lactate during cheesemaking (Huffman and Kristoffersen, 1984). The highest intensity of sweet found in CJ samples is probably due to a lower loss of lactose compared with CC samples. However, the intensity of this taste descriptor in CJ-120 samples decreased by more than $50 \%$ compared with that of CJ-45 samples. This result is probably related to the fermentation of lactose to lactic acid during ripening (McSweeney, 2004; 
Kongo, 2013). The differences found among cheeses for the other taste attributes were due to the ripening time rather than the presence of jenny milk. In particular, less-ripened cheeses had lower scores than more ripened cheeses for salty, bitter, and sour descriptors. These results are consistent with previous studies (Barlow et al., 1989; Muir et al., 1995; Freitas and Malcata, 2000), in which a higher intensity of some basic taste intensified as cheese aged.

Texture was also significantly $(P<0.001)$ affected by the type of cheese, with longer-ripened (120 d) cheese samples showing higher hardness compared with 45 - $\mathrm{d}$ cheese samples. This result is probably due to the decrease of the moisture content of cheeses during ripening. Previous studies (Creamer and Olson, 1982; Amantea et al., 1986; Freitas and Malcata, 2000; Buffa et al., 2001) have reported that the moisture loss led to an increase of cheese firmness during ripening. Based on this explanation, it can be assumed that the decrease in moisture content was probably higher in CJ than in CC samples, as the highest intensity of hardness was found in CJ samples.

Concerning the consumer test, the mean liking scores of the 4 types of cheeses were well above the central point ( $5=$ neither pleasant nor unpleasant) of the 9-point hedonic scale (CJ-45: 6.72; CC-45: 6.07; CJ-120: 5.92; CC-120: 5.74), thus indicating that all the products were appreciated by consumers. However, the differences among the products were statistically significant $(P<0.05)$ : the mean overall liking score was significantly higher for CJ-45 cheese samples than for the other cheese samples. As shown in Table 3, the 45 -d-old cheese made with jenny milk was characterized by the strongest intensity of structure and color uniformity, as well as by the strongest sweet taste. The acceptability of the other cheeses was quite similar each other, as no significant differences were found among their liking ratings. Our results are consistent with a previous study on semihard cheese made with jenny milk (Cosentino et al., 2015), in which no difference for some sensory parameters (color, odor, flavor, and texture) among 120-d-old cheeses made by adding different aliquots of jenny milk during cheesemaking (from 0 to $7.41 \%$ ). The lack of significant differences among cheeses found in Cosentino et al. (2015) is probably related to a decrease of the intensity of the sensory descriptors that characterize the 45 -d-old cheese made with jenny milk.

In conclusion, our results revealed that adding jenny milk during cheese making led to the creation of cheese characterized by characteristic sensory properties. In particular, the intensity of some sensory attributes was quite different between cheeses made with and without jenny milk and it was also affected by ripening time. By sensory and consumer acceptability data analysis, some descriptors related to appearance and taste attributes were found to be distinctive of the 45-d-old cheese made with jenny milk, which was the most preferred by consumers.

Overall, these results are clearly an important step toward the characterization of cheese manufactured by adding jenny milk. However, to obtain a more comprehensive characterization, further studies are needed to evaluate the effect of the addition of jenny milk on chemical and physical composition of cheese.

\section{ACKNOWLEDGMENTS}

This research was supported by Basilicata Region, Potenza, Italy, MIBAF Project PIF, Rural Development Programme 2007-2013, Fund FEASR, Board 1, Measure 124-PIF Green Farms: "Together to raise, transform, marketing and grow in quality with Green Farms."

\section{REFERENCES}

Amantea, G. F., B. J. Skura, and S. Nakai. 1986. Culture effect on ripening characteristics and rheological behaviour of Cheddar cheese. J. Food Sci. 51:912-918.

AOAC. 1990. Official Methods of Analysis. 15th ed. Association of Official Analytical Chemists, Arlington, VA.

Barlow, I., G. T. Lloyd, E. H. Ramshaw, A. J. Miller, G. P. Mccabe, and L. Mccabe. 1989. Correlations and changes in flavour and chemical parameters of cheddar cheeses during maturation. Aust. J. Dairy Technol. 4:7-18.

Braghieri, A., N. Piazzolla, A. Romaniello, F. Paladino, A. Ricciardi, and F. Napolitano. 2015. Effect of adjucts on sensory properties and consumer liking of Scamorza cheese. J. Dairy Sci. 98:14791491.

Buffa, M. N., A. J. Trujillo, M. Pavia, and B. Guamis. 2001. Changes in textural, microstructural and colour characteristics during ripening of cheeses made from raw, pasteurized or high-pressuretreated goats'milk. Int. Dairy J. 11:927-934.

Chambers, D. H., E. Chambers IV, and J. Dallas. 2005. Flavor description and classification of selected natural cheeses. Pages 641-654 in Culinary Arts and Sciences V: Global and National Perspectives. J. S. A. Edwards, B. Kowrygo, and K. Rejman, ed. Worshipful Company of Cooks Research Centre, Bournemouth, Poole, UK.

Cosentino, C., R. Paolino, P. Freschi, and A. M. Calluso. 2012. Short communication: Jenny milk production and qualitative characteristics. J. Dairy Sci. 95:2910-2915.

Cosentino, C., R. Paolino, P. Freschi, and A. M. Calluso. 2013. Short communication: Jenny milk as an inhibitor of late blowing in cheeses: A preliminary report. J. Dairy Sci. 96:3547-3550.

Cosentino, C., R. Paolino, V. Valentini, M. Musto, A. Ricciardi, F. Adduci, C. D'Adamo, G. Pecora, and P. Freschi. 2015. Effect of jenny milk addition on the inhibition of late blowing in semihard cheese. J. Dairy Sci. 98:5133-5142. http://dx.doi.org/10.3168/ jds.2015-9458.

Creamer, L. K., and N. F. Olson. 1982. Rheological evaluation of maturing Cheddar cheese. J. Food Sci. 47:631-646.

Drake, M. A., S. C. Mclngvale, P. D. Gerard, K. R. Cadwallader, and G. V. Civille. 2001. Development of a descriptive language for Cheddar cheese. J. Food Sci. 66:1422-1427.

Drake, M. A., M. D. Yates, and P. D. Gerard. 2005a. Impact of serving temperature on trained panel perception of Cheddar cheese flavor attributes. J. Sens. Stud. 20:147-155. 
Drake, M. A., M. D. Yates, P. D. Gerard, C. M. Delahunty, E. M. Sheehan, R. P. Tumbull, and T. M. Dodds. 2005b. Comparison of differences between lexicons for descriptive analysis of Cheddar cheese flavour in Ireland, New Zealand and the United States of America. Int. Dairy J. 15:473-483.

Fantuz, F., S. Ferraro, L. Todini, R. Piloni, P. Mariani, and E. Salimei. 2012. Donkey milk concentration of calcium, phosphorus, potassium, sodium and magnesium. Int. Dairy J. 24:143-145.

Fratini, F., V. V. Ebani, M. Ampola, E. Innocenti, F. Forzale, M. Periccioli, D. Cerri, and E. Andreani. 2006. Determinazione della concentrazione di lisozima in latte ovino normale e mastitico [Evaluation of lysozyme titration in normal and mastitic ewe milk]. Atti XIV Congresso Internazionale Fe.Me.S.P.Rum- Lugo - Santiago de Compostela (Spagna) edirote Universidade de Santiago de Compostela publicacions.

Freitas, C., and F. X. Malcata. 2000. Microbiology and biochemistry of cheeses with Appélation d'Origine Protegée and manufactured in the Iberian Peninsula from ovine and caprine milks. J. Dairy Sci. 83:584-602.

Galassi, L., E. Salimei, and M. Zanazzi. 2012. Impiego del latte di asina in sostituzione di lisozima da uovo nella produzione del formaggio duro italiano: Prime esperienze. (Grana Padano cheese making with lysozyme from ass's milk: First results.) J. Ital. Dairy Sci. Assoc. 63:73-79.

Gasperi, F., M. Zannoni, and S. Abbà. 2012. I formaggi. Pages 193241 in Atlante sensoriale dei prodotti alimentari. Società Italiana di Scienze Sensoriali, ed. Tecniche nuove, Milano, Italy.

Guo, H. Y., K. Pang, X. Y. Zhang, L. Zhao, S. W. Chen, and M. L. Don. 2007. Composition, physiochemical properties, nitrogen fraction distribution, and amino acid profile of donkey milk. J. Dairy Sci. 90:1635-1643.

Huffman, L. M., and T. Kristoffersen. 1984. Role of lactose in Cheddar cheese manufacturing and ripening. N.Z. J. Dairy Sci. Tech. 19:151-162.

ISO. 2013. Milk and liquid milk products - Guidelines for the application of mid-infrared spectrometry (ISO 9622: 2013/IDF 141:2013). International Organization for Standardization, Geneva, Switzerland.

Kongo, J. M. 2013. Lactic acid bacteria as starter-cultures for cheese processing. Past, present and future developments. Pages 1-20 in Lactic Acid Bacteria - R \& D for Food, Health and Livestock Purposes. In Tec, Rijeka, Croatia. http://dx.doi.org/10.5772/55937.

Koppel, K., E. Chambers IV, and D. H. Chambers. 2011. Flavour and acceptance of Estonian cheeses. Agron. Res. 9:409-414.

Kumari, K., and M. P. Mathur. 1981. Buffalo milk lysozyme. Indian J. Dairy Sci. 34:385-390.

Liggett, R. E., M. A. Drake, and J. F. Delwiche. 2008. Impact of flavor attributes on consumer liking of Swiss cheese. J. Dairy Sci. 91:466-476.

Marseglia, A., A. M. Castellazzi, C. Valsecchi, A. Licari, G. Piva, F. Rossi, L. Fiorentini, and G. L. Marseglia. 2013. Outcome of oral provocation test in egg-sensitive children receiving semi-fat hard cheese Grana Padano PDO (protected designation of origin) containing, or not, lysozyme. Eur. J. Nutr. 52:877-883.

Martemucci, G., and A. G. D'Alessandro. 2012. Fat content, energy value and fatty acid profile of donkey milk during lactation and implications for human nutrition. Lipids Health Dis. 11:113.

McSweeney, P. L. 2004. Biochemistry of cheese ripening. Int. J. Dairy Technol. 57:127-144.

Meilgaard, M. C., B. T. Carr, and G. V. Civille. 2006. Sensory evaluation techniques. CRC Press, Boca Raton, FL.
Montouto-Grana, M., E. Fernandez-Fernandez, M. L. Vazquezoderiz, and M. A. Romero-Rodriguez. 2002. Development of a sensory profile for the specific de nomination "Galician potato". Food Qual. Prefer. 13:99-106.

Muir, D. D., E. A. Hunter, J. M. Banks, and D. S. Horne. 1995. Sensory properties of Cheddar cheese: Changes during maturation. Food Res. Int. 28:561-568.

Nazzaro, F., P. Orlando, F. Fratianni, and R. Coppola. 2010. Isolation of components with antimicrobial property from the donkey milk: A preliminary study. Open Food Sci. J. 4:43-47.

Pagliarini, E. 2002. Valutazione sensoriale. Aspetti teorici, pratici e metodologici. Pages 83-96, Ulrico Hoepli Editore S.p.A., Milano, Italy.

Pagliarini, E., E. Monteleone, and I. Wakeling. 1997. Sensory profile description of mozzarella cheese and its relationship with consumer preference. J. Sens. Stud. 12:285-301.

Papetti, P., and A. Carelli. 2013. Composition and sensory analysis for quality evaluation of a typical Italian cheese: Influence of ripening period. Czech J. Food Sci. 31:438-444.

Pompei, C. E. Casiraghi, M. Lucisano, and C. Dellea. 1991. Characterization of provolone cheese. I. Selection of variables. Ital. J. Food Sci. 3:101-112.

Rétiveau, A., D. H. Chambers, and E. Esteve. 2005. Developing a lexicon for the flavor description of French cheeses. Food Qual. Prefer. 16:517-527.

Ritvanen, T., S. Lampolahti, L. Lilleberg, T. Tupasela, M. Isoniemi, U. Applebye, T. Lyytikäinen, S. Eerola, and E. Uusi-Rauva. 2005. Sensory evaluation, chemical composition and consumer acceptance of full fat and reduced fat cheeses in the Finnish market. Food Qual. Prefer. 16:479-492.

Rohm, H., and D. Jaros. 1996. Colour of hard cheese. Description of colour properties and effects of maturation. Z. Lebensm. Unters. Forsch. 203:241-244.

Ryffel, S., P. Piccinali, and U. Bütikofer. 2008. Sensory descriptive analysis and consumer acceptability of selected Swiss goat and sheep cheeses. Small Rumin. Res. 79:80-86.

Saldo, J., B. Sendra, and B. Guamis. 2002. Colour changes during ripening of high pressure treated hard caprine cheese. High Press. Res. 22:659-663.

Scharfen, E. C., D. A. Mills, and E. A. Maga. 2007. Use of human lysozyme transgenic goat milk in cheese making: Effects on lactic acid bacteria performance. J. Dairy Sci. 90:4084-4091.

Stampanoni, C. R. 1993. The quantitative flavour profiling technique. Chem. Senses 18:19-24.

Stone, H., J. Sidel, S. Oliver, A. Woolsey, and R. C. Singleton. 2004. Sensory evaluation by quantitative descriptive analysis. Pages 23 34 in Descriptive Sensory Analysis in Practice. M. C. Gacula, ed. Food \& Nutrition Press Inc., Trumbull, CT.

Tafaro, A., T. Magrone, F. Jirillo, G. Martemucci, A. G. D'Alessandro, and L. Amati. 2007. Immunological properties of donkey's milk: Its potential use in the prevention of atherosclerosis. Curr. Pharm. Des. 13:3711-3717.

Young, N. D., M. Drake, K. Lopetcharat, and M. R. McDaniel. 2004. Preference mapping of cheddar cheese with varying maturity levels. J. Dairy Sci. 87:11-19.

Zhang, X. Y., L. Zhao, L. Jiang, M. L. Dong, and F. Z. Ren. 2008. The antimicrobial activity of donkey milk and its microflora changes during storage. Food Contr. 19:1191-1195. 